\title{
Atribuições de causalidade para o sucesso e o fracasso escolar dos seus alunos por professoras do ensino fundamental ${ }^{1}$
}

\author{
Mirella Lopez Martini \\ Faculdade de Filosofia, Ciências e Letras de Ribeirão Preto - USP \\ Zilda Aparecida Pereira Del Prette \\ Universidade Federal de São Carlos-UFSCar; Faculdade de Filosofia, Ciências e Letras de Ribeirão Preto - USP
}

\begin{abstract}
Resumo
As interações professor-aluno constituem um momento privilegiado de concretização do pensamento pedagógico do professor e da transmissão, intencional ou não, de suas crenças sobre o aluno e o processo educacional. As atribuições de causalidade enquanto crenças pessoais acerca das causas de um determinado evento podem afetar as características das interações professor-aluno e, por essa via, o desempenho escolar dos alunos. Este estudo investigou as atribuições de causalidade para o sucesso e fracasso escolar dos alunos junto a 30 professoras de $3^{\mathrm{a}}$ série do Ensino Fundamental. Os dados foram coletados por meio de questões abertas e fechadas, foram analisados qualitativa e quantitativamente. Observou-se uma tendência das professoras a atribuírem aos alunos as causas do sucesso e do fracasso escolar, embora reconhecendo a ação docente como fator de desenvolvimento e aprendizagem dos alunos. São discutidos alguns aspectos da relação entre as crenças do professor, sua prática pedagógica e os processos de desenvolvimento e aprendizagem dos alunos, defendendo-se maior investimento no aprofundamento dessa relação.
\end{abstract}

Palavras-chave: interação professor-aluno; atribuição de causalidade; desempenho acadêmico.

\begin{abstract}
Teacher's causal attributions for success and failure of their students

Teacher-student interactions constitute a particular moment to express teachers' pedagogic thoughts and to transmit, intentionally or not, their beliefs about the student and the educational process. As personal beliefs concerning the reasons why certain events occur or not, causal attribution can affect the characteristics of teacher-student's interactions and by this way the students' academic achievement. This study investigated causal attributions for students' success or failure in a sample of 30 high school third grade female teachers. Data were collected using questionnaires and analyzed in qualitative and quantitative ways. The results showed a tendency to consider the students responsible for their academic success and failure, although teachers recognized their educational actions as a factor of students' learning and development. Some aspects of the relationship among the teachers' beliefs, their pedagogic practices and the students' developmental and learning processes are discussed.
\end{abstract}

Keywords: teacher-student's interactions; causal attributions; academic achievement.

As relações entre as crenças e as ações cotidianas das pessoas têm sido alvo de interesse crescente nos últimos anos. Uma das linhas de investigação dessas relações é constituída pelos estudos acerca dos efeitos das atribuições de causalidade sobre os comportamentos das pessoas. No contexto escolar, essas relações podem ser examinadas quando se busca entender a motivação e o desempenho de professores e alunos no processo de ensino e aprendizagem.

As relações entre atribuições de causalidade e desempenho escolar foram amplamente investigadas por Weiner $(1979 ; 1985)$. Sua linha de pesquisa constituiu um referencial teórico básico para o estudo das atribuições de causalidade em contexto escolar nos últimos anos. Para Weiner as experiências de sucesso e fracasso em atividades acadêmicas são geralmente atribuídas a fatores como inteligência, esforço, dificuldade da tarefa, sorte, temperamento, cansaço, influência do professor e influência de outras pessoas. Entretanto, o autor reconhece a possibilidade de uma lista infinita de causas concebíveis para sucesso e fracasso escolar e sugere a criação de um esquema de classificação destas a partir da identificação das semelhanças, diferenças e propriedades básicas das atribuições de causalidade definindo, então, a existência 
de três dimensões das causas: a internalidade (causas internas ou externas ao sujeito), a estabilidade (causas estáveis ou instáveis) e a controlabilidade (causas controláveis ou incontroláveis pelo sujeito).

Com base nas dimensões da causalidade, pode-se dizer que a capacidade, o esforço, o humor e a saúde, entre outras, são consideradas como causas internas ao sujeito, ao passo que a influência do professor, da tarefa e da família são causas externas. Atribuições à capacidade e à família poderiam ser tidas como estáveis, enquanto que esforço e atenção seriam instáveis. Em geral, causas como capacidade, sorte e influência do professor são consideradas incontroláveis mas, por outro lado, o esforço seria uma causa controlável pelo sujeito. Cabe ressaltar que o modo como os indivíduos interpretam uma determinada causa numa dada dimensão é mais importante na determinação do comportamento de realização, do que as causas em si. Todavia, apesar das diferenças individuais, há um certo consenso quando se diferenciam causas internas de externas, instáveis de estáveis e controláveis de incontroláveis (Martini, 1999; Martini \& Boruchovitch, 2001).

As atribuições de causalidade para o sucesso e fracasso escolar, interpretadas nas dimensões da causalidade, influenciam as expectativas, as emoções, a motivação para a aprendizagem, as características das relações professor-aluno e o desempenho de professores e alunos (Weiner, 1979, 1985, 1991; Martini, 1999; Martini \& Boruchovitch, 2001). A estabilidade de uma causa, por exemplo, determina as expectativas de sucesso ou fracasso futuros. A internalidade da causa influencia as reações afetivas, a auto-estima, o orgulho e o autoconceito, entre outras variáveis. A controlablidade exerce efeitos diversos sobre as expectativas, a motivação e as emoções.

\section{As atribuições de causalidade para o sucesso e o fracasso escolar, na perspectiva do professor}

O papel do professor e de suas características tem sido amplamente reconhecido como um dos principais fatores que influem sobre a qualidade das relações professor-aluno e da aprendizagem dos alunos na escola. O conhecimento acadêmico e metodológico dos professores é tradicionalmente defendido como relevante para uma prática pedagógica bem sucedida. Entretanto, pesquisas mais recentes sobre o ensinoaprendizagem passaram a considerar as crenças, as expectativas, os sentimentos e as habilidades de professores de forma mais orgânica e integrada com a prática pedagógica e seus produtos. Portanto, esses aspectos podem afetar as características das relações professor-aluno e, por essa via, o desempenho e o rendimento dos alunos (Weisz, 1999; Almeida, 1995; Leite, 1998; Dias-da-Silva, 1994, Davis, Silva \& Espósito, 1989; Coll \& Miras, 1996; Rosenthal \& Jacobson, 1968; Martini, 1999; Boruchovitch \& Martini,
1997; Boruchovitch, 1995; Martini \& Boruchovitch, 2001; Del Prette, 1990; Del Prette, 1995a; 1995b).

As relações professor-aluno, geralmente iniciadas, mantidas ou concluídas através da mediação direta ou indireta do professor, constituem um momento privilegiado de concretização do seu pensamento pedagógico e da transmissão, intencional ou não, de suas crenças e sentimentos sobre o aluno, sobre as causas responsáveis pelo sucesso e fracasso dos seus alunos na escola, sobre seu próprio papel como professor, sobre a função da escola e tantos outros aspectos importantes do contexto educacional (Coll \& Miras; 1996; Coll \& Solé, 1996; Sacristán \& Gomes, 1998; Del Prette, 1990). Deste modo, o papel de agente e mediador de relações em sala de aula, requerido no trabalho docente, exige do professor não apenas conhecimento acadêmico e habilidades didáticopedagógicas, mas também, um conjunto de crenças e competências que se alimentam reciprocamente (Del Prette \& Del Prette, 1997a; 1997b). Com base nesta perspectiva, a pertinência e adequação de se compreender o sucesso e fracasso escolar, por meio das atribuições de causalidade, vem sendo cada vez mais reconhecida nos estudos realizados nesta área, sobretudo ao constatarem que as atribuições de causalidade dos professores para o sucesso e fracasso escolar dos seus alunos influenciam as expectativas de sucesso e fracasso destes alunos, como também o desempenho acadêmico, as emoções e a motivação dos mesmos (Martini, 1999).

Gama e Jesus (1994) investigaram as atribuições de causalidade e as expectativas de professores sobre o desempenho escolar de seus alunos de escolas públicas. Verificou-se um deslocamento das atribuições para o fracasso escolar do âmbito da escola e do professor para o campo de responsabilidade individual do aluno e de sua família (mais especialmente o interesse, esforço e condições econômicas de seus integrantes). Os alunos considerados pelo professor como menos inteligentes não apenas geravam expectativas de que o seu desempenho final seria baixo, como também eram sistematicamente reprovados. Em estudos semelhantes, Maluf e Bardelli (1991) e Neves e Almeida (1996) demonstraram que, em geral, professoras do ensino fundamental atribuem o mau rendimento escolar dos seus alunos a causas familiares e a problemas de saúde física. Juvonen (1988) verificou que os professores vêem as causas do fracasso dos alunos como estáveis, reduzindo as expectativas de sucesso do aluno e elevando as de fracasso. Na mesma linha, Givvin, Stipek, Salmon e Mac Gyvers (1998) verificaram que o professor parece ter uma visão da motivação do aluno como algo estável e incontrolável, o que pode impedi-lo de perceber possíveis estratégias de intervenções e mudanças em alunos com dificuldades motivacionais. Essas expectativas transformam-se 
em teorias acabadas sobre o desempenho dos alunos e em profecias de auto-realização.

Em síntese, pode-se afirmar que as atribuições de causalidade dos professores afetam as relações professor-aluno e, por esta via, a aprendizagem e o desenvolvimento socioemocional dos alunos, justificando o investimento em identificar e intervir sobre esses aspectos em nosso meio, sobretudo ao se levar em consideração o reduzido número de pesquisas nessa área com professores brasileiros do ensino fundamental (Martini, 1999). Como as atribuições de causalidade são passíveis de mudança, esse conhecimento pode oferecer importantes subsídios para a análise de condições objetivas de produção de crenças inapropriadas e para a criação de novas condições geradoras de um contexto simbólico mais favorável ao sucesso escolar.

Com base nessas considerações, o objetivo deste estudo foi investigar atribuições de causalidade de professores do Ensino Fundamental para situações de sucesso ou fracasso escolar dos seus alunos.

\section{MÉTODO}

\section{Participantes}

Participaram deste estudo 33 professoras, com idade média de 35 anos, da $3^{\text {a }}$ série do ensino fundamental, de nove escolas da rede pública de São Carlos, escolhidas segundo o critério de aceitação para participação no estudo. As escolas participantes abarcavam razoavelmente os diferentes pontos da cidade (de centro e de periferia) e incluíram nove das onze pela Delegacia de Ensino. As professoras constituíram o total de $3^{\mathrm{a}}$ série dessas escolas.

\section{Instrumento}

Os dados sobre as atribuições de causalidade das professoras para sucesso ou fracasso escolar dos seus alunos foram coletados por meio de um Questionário de Atribuições de Causalidade (QAC-P), composto de duas partes:

A primeira parte era formada por questões abertas e continha cinco situações de fracasso escolar e cinco situações de sucesso escolar dos alunos. Os professores deveriam, então, imaginar que essas estórias eram sobre eles e seus alunos e, em seguida, avaliar as possíveis causas responsáveis pelos desempenhos bem ou mal sucedidos dos alunos.

$\mathrm{Na}$ primeira situação os alunos não conseguiram fazer uma lição, na segunda, terceira e quarta situações, alunos de alto, baixo e médio desempenho acadêmico, respectivamente, tiveram notas baixas em um prova e, na quinta situação, os alunos não compreenderam a matéria dada em sala de aula. Situações exatamente opostas a essas foram apresentadas para verificação das atribuições de causalidade para sucesso escolar. Os trabalhos de elaboração, revisão e refinamento do instrumento foram baseados num exame detalhado da literatura da área (Martini, 1999).

A segunda parte era composta de questões fechadas e apresentava um conjunto de 13 afirmações, nas quais os sucesso e fracasso escolar dos alunos estavam relacionados a fatores tais como as características familiares e emocionais do aluno, à facilidade da tarefa acadêmica, à sorte do aluno, à capacidade ou falta de capacidade do aluno, à ajuda ou falta de ajuda do professor. Os professores deveriam, então, assinalar se concordavam ou discordavam dessas afirmações.

\section{Procedimento de coleta de dados}

Inicialmente solicitou-se às escolas uma sala para a aplicação do QAC-P e um horário onde todos os professores pudessem ser convocados para responderem simultaneamente, embora individualmente, aos questionários.

$\mathrm{Na}$ aplicação do questionário, após breve rapport, a pesquisadora explicou os objetivos da pesquisa, referindo-se genericamente a uma investigação sobre crenças e sentimentos de professores do ensino fundamental, garantindo o sigilo e pedindo que respondessem o mais sinceramente possível, pois não deveriam se preocupar com respostas certas ou erradas mas em expressarem suas opiniões sobre os assuntos tratados. A aplicação durou cerca de 50 minutos e, embora a pesquisadora permanecesse na sala avisando que estaria disponível para eventuais dúvidas, estas foram raras.

\section{Tratamento dos dados}

Em relação aos itens da primeira questão, as causas atribuídas pelas professoras foram objeto de análise de conteúdo e organizadas segundo as categorias encontradas na literatura da área (Martini, 1999; Neves \& Almeida, 1996; Weiner, 1979). Como as professoras podiam dar mais de uma resposta em cada situação, computou-se a freqüência das respostas nas diferentes categorias atribucionais e a proporção de professores que a utilizaram.

As respostas das professoras às questões fechadas da segunda parte foram computadas em termos da porcentagem de concordâncias às afirmações apresentadas em cada item, ou seja, às diferentes categorias de explicações dadas para sucesso e fracasso escolar.

\section{RESULTADOS E DISCUSSÃO}

As explicações dadas pelas professoras na primeira parte do QAC-P foram organizadas conforme as classes de atribuições encontradas na literatura, compu- 
tando-se o a percentagem de professoras que utilizaram cada uma delas.
A porcentagem de professoras, segundo as categorias de atribuições utilizadas para explicar o sucesso escolar, é apresentada na Tabela 1.

Tabela 1 - Porcentagens de professoras identificadas nas diferentes classes de atribuições de causalidade para sucesso escolar dos alunos, nas cinco situações apresentadas

\begin{tabular}{lcrrrrr}
\hline \multirow{2}{*}{ ATRIBUIÇÕES DE CAUSALIDADE } & \multicolumn{5}{c}{ HISTÓRIAS DE SUCESSO ESCOLAR DOS ALUNOS } \\
& Fizeram bem uma & \multicolumn{2}{c}{ Tiraram boa nota em uma prova } & Entenderam bem uma aula \\
\cline { 3 - 5 } & 75,76 & 75,76 & 48,48 & 33,33 & 12,12 \\
\hline Capacidade do aluno & 48,48 & 51,52 & 39,39 & 51,52 & 42,42 \\
Esforço do aluno & 0,00 & 0,00 & 6,06 & 9,80 & 9,09 \\
Facilidade da tarefa & 9,09 & 6,06 & 21,21 & 27,27 & 81,82 \\
Ajuda do professor & 6,06 & 3,03 & 12,12 & 21,21 & 3,03 \\
Características emocionais do aluno & 6,06 & 27,27 & 3,03 & 6,06 & 3,03 \\
Características familiares do aluno & & & & & \\
\hline
\end{tabular}

Verificou-se que a categoria Capacidade do aluno foi a explicação predominante na situação em que todos fizeram uma boa lição $(75,76 \%)$ e também em que os alunos de alto $(75,76 \%)$ e médio $(48,48 \%)$ desempenho tiraram boas notas na prova. Porém, nos casos dos alunos de baixo desempenho escolar, a explicação predominante foi o Esforço (51,52\%), que aparece em segundo lugar nos casos anteriores. As demais atribuições estão presentes em proporções inferiores. Na situação em que os alunos entenderam bem uma aula, o professor atribuiu a si mesmo a maior parte do sucesso, destacando a categoria Ajuda do professor $(81,82 \%)$ e atribuindo o sucesso, em proporções bem menores, à Capacidade $(12,12 \%)$ e ao Esforço $(42,42 \%)$ do aluno.

Tabela 2 - Porcentagens de professoras identificadas nas diferentes classes de atribuições de causalidade, para fracasso escolar dos alunos, nas cinco situações apresentadas

\begin{tabular}{|c|c|c|c|c|c|}
\hline \multirow{3}{*}{ ATRIBUIÇÕES DE CAUSALIDADE } & \multicolumn{5}{|c|}{ HISTÓRIAS DE FRACASSO ESCOLAR DOS ALUNOS } \\
\hline & \multirow{2}{*}{ Fizeram mal uma lição } & \multicolumn{3}{|c|}{ Tiraram nota baixa em uma prova } & \multirow{2}{*}{ Não entenderam uma aula } \\
\hline & & Alto & Médio & Baixo & \\
\hline Falta de capacidade do aluno & 81,82 & 48,48 & 39,39 & 60,61 & 18,18 \\
\hline Falta de esforço do aluno & 57,52 & 54,55 & 54,55 & 39,39 & 54,55 \\
\hline Dificuldade da tarefa & 0,00 & 0,00 & 12,12 & 0,00 & 36,36 \\
\hline Falta de ajuda do professor & 6,06 & 15,15 & 24,24 & 15,15 & 60,61 \\
\hline Características emocionais do aluno & 6,06 & 57,58 & 24,24 & 18,18 & 15,15 \\
\hline Características familiares do aluno & 6,06 & 15,15 & 18,18 & 9,09 & 0,00 \\
\hline
\end{tabular}

De acordo com os dados da Tabela 2, na situação em que os alunos fazem mal uma lição e em que os alunos de baixo desempenho escolar tiram uma nota baixa, a Falta de capacidade do aluno $(81,82 \%$ e $60,61 \%$ respectivamente) foi a categoria predominante para a explicação do fracasso pelos professores. O professor atribuiu as notas baixas dos alunos de alto desempenho escolar às Características emocionais
É interessante observar, também, que as características socioemocionais são praticamente ignoradas pelos professores na explicação do sucesso escolar dos alunos. A categoria Características familiares do aluno $(27,27 \%)$ destaca-se apenas na explicação das notas boas obtidas pelos alunos de alto desempenho escolar em uma prova, e a categoria Características emocionais do aluno $(21,21 \%)$ aparece em proporções ligeiramente maiores na situação em que os alunos de baixo rendimento acadêmico tiram boas notas na prova.

A Tabela 2 apresenta a proporção professoras nas diferentes classes de atribuições explicativas, para as situações de fracasso escolar dos alunos.
$(57,58 \%)$, e dos alunos de médio desempenho à Falta de esforço $(54,55 \%)$.

$\mathrm{Na}$ situação em que os alunos não entenderam bem uma aula, o professor também atribuiu a si mesmo o fracasso do aluno (Falta ajuda do professor 60,61\%), embora em proporção menor do que no caso de sucesso (Tabela 1).

Do mesmo modo que nas situações de sucesso escolar, as características socioemocionais são pratica- 
mente ignoradas pelos professores na explicação do fracasso escolar dos alunos, exceto para justificar nota baixa dos alunos de alto rendimento. As características familiares do aluno também foram pouco referidas.

Os resultados referentes à segunda questão, baseiamse na percentagem de professores que concordaram com cada uma das 13 afirmações explicativas dadas, que abordavam as diferentes classes de atribuições.

A Tabela 3 reúne as afirmações apresentadas aos professores e a porcentagem de professoras que concordaram com cada item.

Tabela 3 - Porcentagem de concordâncias (c) das professoras acerca das crenças educacionais apresentadas sob a forma de afirmações

\begin{tabular}{|c|c|c|}
\hline CRENÇAS EDUCACIONAIS & ITENS & C \\
\hline $\begin{array}{l}\text { Características familiares do } \\
\text { aluno em situações de fracasso }\end{array}$ & $\begin{array}{l}\text { Quando o aluno não consegue aprender é porque os pais não colaboram com o estudo dos filhos } \\
\text { em casa. }\end{array}$ & 39,39 \\
\hline Facilidade da tarefa & Quando grande parte dos meus alunos tira boas notas é porque a matéria foi fácil. & 3,03 \\
\hline Falta de sorte do aluno & Quando um aluno estuda a matéria, mas tira uma nota ruim na prova, é porque não teve sorte. & 3,03 \\
\hline \multirow{3}{*}{ Falta de capacidade do aluno } & Se um aluno não apreende a explicação da matéria é porque não tem capacidade. & 0,00 \\
\hline & Para adequar o ensino às crianças mais pobres preciso exigir menos delas em sala de aula. & 12,12 \\
\hline & $\begin{array}{l}\text { A inteligência das crianças é praticamente constante e, portanto, elas não ficam mais inteligentes } \\
\text { com o tempo }\end{array}$ & 15,15 \\
\hline Falta de ajuda do professor & $\begin{array}{l}\text { Se um aluno não aprendeu a explicação da matéria é porque o professor não soube explicar da } \\
\text { melhor forma. }\end{array}$ & 18,18 \\
\hline \multirow{2}{*}{$\begin{array}{l}\text { Características emocionais do } \\
\text { aluno }\end{array}$} & $\begin{array}{l}\text { Mesmo que eu me esforce, não terei bons resultados com aqueles alunos que apresentam pro- } \\
\text { blemas na escola ou que estão desmotivados. }\end{array}$ & 27,27 \\
\hline & Quando o aluno não é motivado por si só, o professor pouco pode fazer por ele. & 15,15 \\
\hline \multirow{4}{*}{ Ajuda do professor } & $\begin{array}{l}\text { Todo professor pode conseguir que seu aluno esteja motivado e aprenda na escola, mesmo que a } \\
\text { família não coopere para isso. }\end{array}$ & 87,88 \\
\hline & $\begin{array}{l}\text { Embora o professor trabalhe em sala de aula com cerca de } 40 \text { alunos, ele pode atender a muito } \\
\text { das necessidades individuais destes alunos. }\end{array}$ & 54,55 \\
\hline & A escola pode ajudar a promover o desenvolvimento social e emocional dos alunos. & 100,00 \\
\hline & Muito da aprendizagem dos alunos depende do meu aperfeiçoamento contínuo. & 100,00 \\
\hline
\end{tabular}

A análise da Tabela 3 permite constatar que os maiores índices de concordância das professoras ocorreram nas afirmações que associaram a ajuda do professor ao sucesso do aluno, e os menores índices de concordância nas afirmações que explicam o fracasso pela falta de capacidade e sorte dos alunos e nas que justificam o sucesso em termos do tipo de conteúdo ou a tarefa escolar. Apesar de as professoras destacarem a sua ajuda como fator importante do sucesso do aluno, parecem não concordar que a falta desta mesma ajuda pode dificultar a aprendizagem dos alunos. Há, portanto, um reconhecimento pelas professoras de suas próprias ações como fator de aprendizagem, porém unicamente nos caso onde o desempenho dos alunos é satisfatório.

\section{À GUISA DE CONCLUSÃO}

Na primeira parte do QAC-P o sucesso e fracasso no processo ensino-aprendizagem foram compreendidos pelas professoras como sendo primordialmente de responsabilidade dos alunos. A maioria dos respondentes, ainda que atribuindo, em algumas situações, a responsabilidade pelo sucesso e fracasso dos alunos à Ajuda ou Falta de ajuda do professor, não parece reconhecer seu papel fundamental como agente e mediador do processo ensino-aprendizagem, contrarian- do o reconhecimento da importância de seu desempenho e habilidades, verificado nas respostas da segunda parte do questionário.

Nas situações de sucesso escolar, as professoras atribuíram o bom desempenho dos alunos principalmente à capacidade e esforço dos próprios alunos. A atribuição de capacidade e esforço em situações de sucesso, quando associadas a estratégias de aprendizagem adequadas são atribuições internas ao sujeito e favoráveis ao sucesso escolar, na medida em que podem contribuir o autoconceito positivo dos alunos, promovendo o sentimento de competência no processo de aprendizagem e ajudando os alunos a permanecerem motivados na realização das atividades acadêmicas, o que contribui para um melhor desempenho escolar (Boruchovitch \& Martini, 1997; Martini, 1999).

Em contrapartida, os professores explicaram o fato de os alunos não fazerem bem uma lição e também de os alunos de baixo desempenho escolar não tirarem boas notas à falta de capacidade. A falta de capacidade, geralmente reconhecida como uma causa interna e incontrolável ao sujeito, revela dúvida sobre a competência acadêmica dos alunos e, sendo também considerada como uma causa predominantemente estável, contribui para problemas comportamentais, de apren- 
dizagem e de motivação dos mesmos ao promoverem baixa expectativa de sucesso futuro e superação do fracasso nas atividades escolares (Weiner, 1979), além de possivelmente conduzir o professor ao imobilismo e à passividade, ou seja, a não buscar estratégias alternativas para resolver o problema no processo de ensino-aprendizagem. Ressalta-se, aqui, que este padrão atribucional pode trazer consequiências negativas à condução do processo de ensino-aprendizagem, pois contribui para que o professor se sinta sem condições para lidar com a realidade que enfrenta no cotidiano escolar.

Como apontam Boruchovitch (1994) e Boruchovitch e Martini (1997), quando se pensa em atribuições de causalidade e sucesso escolar, o esforço é um dos fatores fundamentais, principalmente por estar sob controle do sujeito e ser uma causa predominantemente instável. A persistência para a realização de uma tarefa e as expectativas de sucesso futuro parecem aumentadas quando atribuições de falta de capacidade para o fracasso são alteradas para falta de esforço ou para barreiras externas temporárias (Boruchovitch \& Martini, 1997). O professor que valoriza o esforço, tanto o seu próprio como o do aluno, está ampliando as possibilidades de o aluno sentir-se capaz de enfrentar os desafios e dificuldades escolares. Porém, os programas de retreinamento das atribuições de causalidade como intervenções que visam mudar o modo como os alunos interpretam suas experiências de sucesso e fracasso, principalmente quando as causas atribuídas para os eventos escolares não se revelam compatíveis com a motivação para a aprendizagem e com o desempenho acadêmico satisfatório precisam evitar a transmissão para os alunos de mensagens ambivalentes quanto à importância do esforço (Boruchovitch \& Martini, 1997). Tem-se, como exemplo, uma situação onde o aluno está confiante de ter se esforçado ao máximo em uma tarefa e recebe do professor o feedback de fracasso como decorrente da falta de esforço. Este aluno pode, devido à ênfase na falta de esforço, começar a sentir-se incapaz em relação à tarefa (Ames, 1990).

Inúmeras são as implicações educacionais desses resultados, tanto no que se refere à formação de professores, quanto à prática docente e as suas repercussões no desenvolvimento, aprendizagem e motivação dos alunos. A tendência de os professores em atribuírem aos alunos as causas do sucesso ou fracasso escolar sugere uma postura determinista e um estado de passividade pedagógica que é incoerente com o reconhecimento do processo educacional como fenômeno multideterminado e a atuação do professor como fator do sucesso e fracasso escolar. Além disso, revela um desconhecimento das relações entre suas atribuições de causalidade para o sucesso ou fracasso escolar e os processos de desenvolvimento e aprendizagem dos seus alunos.

Entende-se que é fundamental que os professores se tornem conscientes de suas crenças e do efeito delas sobre sua prática e sobre o desempenho dos alunos e que sejam assessorados no sentido de ampliarem os seus esquemas de análise de modo a reconhecerem outros fatores que, por estarem mais diretamente sob controle do aluno e de sua atuação, contribuem para o sucesso escolar.

Esses resultados se contrapõem, em parte, aos dados da primeira questão do QAC-P, na qual o professor atribui sobretudo aos alunos as causas do sucesso ou fracasso, ao destacarem que as professoras concordam muito pouco com a explicação do fracasso escolar como decorrência da falta de capacidade do aluno e valorizam bastante o seu próprio papel como elemento decisivo para o sucesso escolar dos alunos, revelando, até certo ponto, a assimilação de um discurso educacional que ressalta a importância da escola, e especialmente do professor, para o desenvolvimento e aprendizagem. Entretanto, essas professoras não reconhecem, nas situações de fracasso escolar, o papel que exercem como elemento fundamental do processo de ensino-aprendizagem, possivelmente numa tentativa de preservarem o seu próprio autoconceito e a auto-eficácia no trabalho.

Pode-se perceber, na análise desses dados, a possibilidade de os professores reconhecerem-se como ativos no processo educacional e não acentuarem as dificuldades e inadequações dos alunos. Todavia, observou-se um discurso contraditório das professoras ao se comparar os dados das duas questões do QAC-P (a primeira, com questões abertas em uma situação de análise, e a segunda com questões fechadas em situação de concordância/discordância), o que aponta para a importância de estudos que explorem diferentes indicadores de atribuições, como se tentou fazer neste trabalho.

\section{REFERENCIAS}

Almeida, N. V. F. (1995). Papel do pesquisador como mediador no processo de construção de conhecimento do professor. Temas de Psicologia, 1, 1-10.

Ames, C. (1990). Motivation: What teacher need to know. Teacher College Record, 91, 409-421.

Boruchovitch, E. (1994). As variáveis psicológicas e o processo de aprendizagem: Uma contribuição para a psicologia escolar. Psicologia: Teoria e Pesquisa, 10(1), 129-139.

Boruchovitch, E. (1995). A identificação e o estudo das variáveis associadas ao fracasso escolar brasileiro. Projeto de recém-doutor do CNPq. Departamento de Psicologia Educacional, UNICAMP.

Boruchovitch, E. (1998). Causal attributions for success and failure in mathematics: A cross-cultural analysis. 
Paper apresentado no $24^{\text {th }}$ International Congress of Applied Psychology, San Francisco, 9-14.

Boruchovitch, E. \& Martini, M. L. (1997). As atribuições de causalidade para o sucesso e fracasso escolar e a motivação para aprendizagem de crianças brasileiras. Arquivos Brasileiros de Psicologia, 49(3), 59-71.

Coll, C. \& Miras, M. (1996). Características individuais e condições de aprendizagem: A busca de interações. Em: C. Coll; J. Palácios \& A. Marchesi (Orgs.), Desenvolvimento psicológico e educação. Psicologia da educação (p. 353-373). Artes Médicas: Porto Alegre, vol. 2.

Coll, C., \& Solé, I. (1996). A interação professor/aluno no processo de ensino e aprendizagem. Em: C. Coll, J. Palácios \& A. Marchesi (Orgs.), Desenvolvimento psicológico e educação. Psicologia da educação (p. 281297). Artes Médicas: Porto Alegre, vol. 2.

Davis, C.; Silva, M. A. S. \& Espósito, Y. (1989). Papel e valor das interações sociais em sala de aula. Cadernos de Pesquisa, 71, 49-54.

Del Prette, Z. A. P. (1990). Uma análise da ação educativa do professor a partir de seu relato verbal e da observação em sala de aula. Tese de doutorado. Instituto de Psicologia, Universidade de São Paulo.

Del Prette, Z. A. P. (1995). Subcultura escolar: Desafios à atuação do psicólogo escolar. Anais do XVII International School Psychology Colloquium e II Congresso Nacional de Psicologia Escolar. Campinas: Átomo, vol. 2, 254-257.

Del Prette, A. \& Del Prette, Z. A. P. (1995). Interações sociais em sala de aula: representações do professor. Anais da XVII International School Psychology Colloquium e II Congresso Nacional de Psicologia Escolar, 426-430.

Del Prette, Z. A. P. \& Del Prette, A. (1997a). Habilidades sociais e construção do conhecimento em contexto escolar. Em: D. R. Zamignani (Org.), Sobre comportamento e cognição: A aplicação da Análise do Comportamento e da Terapia Cognitivo-Comportamental no hospital geral e nos transtornos psiquiátricos (p. 234250). São Paulo: Airbytes.

Del Prette, Z. A. P. \& Del Prette, A. (1997b). Um programa de desenvolvimento de habilidades sociais na formação continuada de professores. Em: Associação Nacional de Pesquisa em Educação (Org.), CD-Rom dos trabalhos selecionados para apresentação para o grupo de formação continuada de professores, 29 páginas, $20^{\mathrm{a}}$ Reunião anual da ANPED, Caxambu, MG.

Dias-da-Silva, M. H. G. (1994). Sabedoria docente: Repensando a prática pedagógica. Cadernos de Pesquisa, 89, 39-47.

Gama, E. M. P. \& Jesus, D. M. (1994). Atribuições e expectativas do professor: representações sociais na manutenção da seletividade social na escola. Psicologia: Teoria e Pesquisa, 10(3), 393-410.

Givvin, K. B.; Stipek, D. J.; Salmon, J. M. \& Mac Gyvers, V. L. (1998). In the eyes of the beholder: Students' and teacher's judgments of students' motivation (Texto Mímeo).

Juvonen, J. (1988). Outcome and attributional disagreements between students and their teacher. Journal of Educational Psychology, 80(3), 330-336.

Leite, S. A. da S. (1998). Prefácio. Em: A. M. F. A. Sadalla (Org.), Com a palavra a professora: Suas crenças, suas ações. Campinas: Alínea.

Maluf, M. R. \& Bardelli, C. (1991). Que valor o professor atribui a capacidade e resultado obtido pelos alunos em contexto de realização escolar? Arquivos Brasileiros de Psicologia, 36(4), 132-41.

Martini, M. L. (1999). Atribuições de causalidade, crenças gerais e orientações motivacionais de crianças brasileiras. Dissertação de mestrado. Departamento de Psicologia Educacional da Faculdade de Educação da UNICAMP.

Martini, M. L. \& Boruchovitch, E. (1999). Causal attributions for academic success and failure of Brazilian children. Paper presented at the VI European Congress of Psychology, Rome, 284.

Martini, M. L. \& Boruchovitch, E. (2001). Atribuições de causalidade: A compreensão do sucesso e fracasso escolar por crianças brasileiras. Em: J. A. Bzuneck e E. Boruchovitch (Orgs.), A motivação do aluno: Contribuições da Psicologia Contemporânea (p. 148-166). Petrópolis: Vozes.

Neves, M. B. J. \& Almeida, S. F. C. (1996). O fracasso escolar na $5^{\mathrm{a}}$ série, na perspectiva de alunos repetentes, seus pais e professores. Psicologia: Teoria e Pesquisa, 12(2), 147-156.

Rosenthal, R. \& Jacobson, L. (1968). Pygmalion in the classroom. New York: Holt, Rinehart e Winston.

Sacristán, J. G. \& Gomes, A. (1998). Compreender e transformar o ensino. Porto Alegre: Artes Médicas.

Weiner, B. (1979). A theory of motivation for some classroom experiences. Journal of Educational Psychology, 71(1), 3-25.

Weiner, B. (1985). An attributional theory of achievement motivation and emotion. Psychological Review, 92(4), 548-573.

Weiner, B. (1991). Metaphors in motivation and attribution. American Psychologist, 46(9), 921-930.

Weiner, B. (1993). On sin versus sickness. A theory of perceived responsibility and social motivation. American Psychologist, 48(9), 957-965.

Weizs, T. (1999). O diálogo entre o ensino e a aprendizagem. São Paulo: Ática.
Recebido: 20.06 .2002

Revisado: 14.10 .2002

Aceito: 22.11.2002 


\section{Nota:}

${ }^{1}$ Este trabalho é parte do projeto de doutorado da primeira autora, orientada pela segunda, com bolsa da FAPESP (Processo 00/08607-1).

\section{Sobre as autoras}

Mirella Lopez Martini: Psicóloga, Mestra em Psicologia Educacional. Afiliação Institucional: Faculdade de Filosofia, Ciências e Letras de Ribeirão Preto - USP. Endereço para correspondência: Rua XV de Novembro 1.168, Centro, São Carlos, SP - CEP: 13561-160. E-mail: milopez@zaz.com.br

Zilda Aparecida Pereira Del Prette: Psicóloga, Doutora em Psicologia Experimental (USP). Afiliação Institucional: Universidade Federal de São Carlos-UFSCar; Faculdade de Filosofia, Ciências e Letras de Ribeirão Preto - USP. E-mail: zdprette@ power.ufscar.br 